\title{
An Equity Analysis of Scholarships and Loans in Financing Students' Tertiary Education in the Sarawak Corridor of Renewable Energy (SCORE) Region
}

\author{
Lau, Hieng Soon \\ School of Business and Management, University College of Technology Sarawak, \\ Sibu, Sarawak, Malaysia \\ lau.hs@ucts.edu.my
}

\begin{abstract}
This paper examines the equity of scholarships and student loans at the two private Institutions of higher learning in the Sarawak Corridor of Renewable Energy (SCORE) region. Surveys involving undergraduates of two private institutions of higher learning were conducted. Using cross-tabulation, the equality of scholarship and loan distributions to undergraduates with reference to four independent variables: ethnicity, gender, areas of origin and income groups were investigated. Chi-square test was used to examine associations between the provision of scholarships and loans and the four independent variables. By employing cross-tabulation and multiple logistic regression, the scholarship distributions favour male over female and urban over rural respectively in terms of type- 1 and type- 2 equality measurements. However, cross-tabulation analysis shows that the scholarship distribution favours native in terms of type- 1 equality but non-natives for type- 2 equality. Multiple regression analysis also indicated that native had more scholarship support than non-natives. For the income groups, both cross-tabulations and multiple regression analyses yielded similar results whereby the high income group received most scholarship, followed by the top-bracket, lowest, low and medium income groups. For the loan distribution, cross-tabulations and multiple logistic regressions indicated that loans favour non-natives over natives, female over male and urban over rural respectively in terms of type-1 and type- 2 equality measurements. However, for the income groupings, it showed mixed results respectively when using both analyses. The result also indicated that the probability for students to get scholarships and loans contrast distinctly with one another with given characteristics. Moreover, respondents highly supported the issues surrounding loans as an alternative mechanism of financing tertiary education. To ease the budgetary pressure and for equity and efficiency reasons, it is suggested an income-contingent loans can be introduced as a student financial support.
\end{abstract}

Keywords: Equity, Financing, Loans, Scholarship, Tertiary Education, SCORE

\section{Introduction}

Education has been advocated by many economists as a worthwhile investment which yields the best interest (Benjamin Franklin, Poor Richar's Almamack, cited by Cohn \& Geske, p70, 1990). According to Human Capital theory, higher education 
enhances productivity and hence raises the earnings of individuals and contributes to economic growth (Cohn \& Geske, 1990, as cited by Lau, 2001; Brewer et al, 2010). Thus, education may enhance human capital Clive (2015).

Traditionally, the overall aim of the higher education sector was to provide education to an elite group of students who would be needed by the economy, especially in the developing countries (Lau, 2001). Since the numbers pursuing higher education were limited, the overall public expenditure or subsidy was low. However, with rapid technological, economic and cultural change, the demand for graduates in disciplines such as science and technology, law, humanities and social science has increased tremendously (Wilson, 1996). In the developed world too, with rising demand for skilled labour has also escalating the demand for higher education (Murphy, Scott-Clayton, \& Wyness, 2018). This means that there is a rising demand for university education both by individuals and the state, accelerated by the political decision to democratise education, leading to a continuous rapid expansion of the higher education sector. Thus, the democratisation of education in Malaysia in the 1990s has changed the elitist secondary education from being elitist to being universal. This is particularly for the case of Sarawak who only had the first public university established in 1992 to cater the rising needs of tertiary education.

However, as higher education policy shifts from supporting elitist to mass participation, governments globally are facing budgetary constraints. These are especially acute in times of economic crisis and structural adjustments. To overcome financial constraints, universities globally have to utilise existing resources more efficiently without additional allocations, or find new sources of finance. The former option includes an increase in the student to staff ratio, more efficient use of the infrastructure and more time devoted to research consultancies for the private sector. But, such changes may be at the expense of the quality of education. Thus, Wilson (1996) argues that that there is a world-wide consensus on the need to find new sources of funding in order to maintain the quality of education.

Many countries therefore have introduced cost-recovery methods such as loan schemes to raise funds from participating students. Various types of loan programmes have been implemented. One is mortgage-type loans whereby repayment is made over a specified period, usually with fixed monthly payments; interest rates and the maximum length of repayment are used to calculate the fixed periodic payments. Interest rates may be partly or fully subsidised by governments. An alternative type of loan is the incomecontingent loan in which loans are repaid as a proportion of a graduate's income each year, organised via either income tax or national insurance contributions. From this perspective, higher education institutions may regard students as consumers, while students may see university education as an investment, rewarded with future high monetary and non-monetary benefits (Wilson, 1996; Eide \& Showalter, 2010).

However, the idea of borrowing for learning, contrasting with the traditional system of grants and scholarships, has reignited a heated argument among economists of education on whether the provision of student loans to supplement or replace the grant scheme eventually is better than the existing grant system in terms of equity and efficiency. Thus, such changes have been the subject of controversy and debate (Woodhall, 2007). The whole debate raises the question who should and how to pay for higher education? Some argue that "he who benefits from the education should pay for it". Others propose that the state should pay, since education can be regarded as a "public good". Society and taxpayer should also contribute since higher education would benefit both the individuals and society as a whole. 
The main purpose of this study is to investigate the equity of student financial support particularly the student loan and scholarship system in the social political context of Malaysia with special reference to the SCORE Region of Sarawak.

\section{Research Questions}

- How equitable are the scholarships and loans in financing privately tertiary education at the SCORE region of Sarawak?

- How do scholarships and loans differ in terms of probability by employing multiple logistic regression analysis?

- What are the opinions of undergraduates on their preferences about alternative options (involving cost-recovery) for financing tertiary education at the SCORE region of Sarawak?

\section{The Problem Statement}

As this study is concerned with public investment in education, the ideas of welfare economics will be used in its arguments. Fundamental question addressed in the study is:

"Is the system equitable?" This question will then relate to questions such as "Who pays the cost? Who benefits? Who should pay? "How can student financial support play a role in equalising college opportunities for the low-income and other disadvantaged, previously excluded groups in the society?" In the light of financial constraints, it is significant to examine these issues.

\section{Literature Review}

The basic question concerns the equity aspect of financing higher education is: "Is the system fair or equitable"? Hence, equity is concerned with the distribution of what is produced and how fair or equitable that distribution is (Mace, 1987,). Questions about equity are much more clearly subjective and value-laden (Lau, 2001).

Barr (1989) defines equity as "Equality of Opportunity", which means equal opportunity of access to education for individuals who have similar tastes and abilities. Each of them should receive the same education, irrespective of extraneous considerations such as race, sex, social class or personal income. Therefore, an individual who has academic ability should not be barred from receiving higher education because of financial or any other reasons. However, this does not mean that each equally qualified person will receive the same quantity of education, since individuals differ in their preferences and aptitudes.

Psacharopolous and Woodhall (1989) suggests that a distinction between normative and positive statements regarding equity should be made clearly. They argue that equity is not only concerned with distribution of resources among different groups but also on normative judgements about how society should distribute resources. There should be clear definitions of groups and measurements for equity. The literature also classifies normative judgement on equity into three types. These are the horizontal equity, requiring "equal treatment of equals." However, there can be no "equal treatment of equals" dictum in the real world as no two individuals are the same (Monk, 1990). Consequently, the concept of vertical equity, requiring "unequal treatment of unequals" is proposed, whereby different groups are treated unequally because of differential needs. 
However, Monk (1990) raises a number of questions regarding moral obligation for the vertical equity argument.

"How responsible are people today for the morally repugnant inequalities that existed in the past among the races?" "Is the magnitude of moral indignation relevant to the obligation to provide compensation?" "Is the magnitude of the previous discrimination, apart from the moral issue, relevant to the obligation to provide compensation?" (Monk, 1990:38)

Intergenerational equity is the concept or idea of fairness or justice between generations. It says that humans 'hold the natural and cultural environment of the Earth in common both with other members of the present generation and with other generations, past and future' (Weiss, 1990, p. 8). It means that we inherit the Earth from previous generations and have an obligation to pass it on in reasonable condition to future generations.

Equity may also be defined as requiring a redistribution of resources designed to achieve the community's philosophical and ethical standard of fairness (McMahon, 1982). Thus, we should consider whether education has a redistributive effect, either regressive or progressive, towards different income groups, genders and ethnic groups.

This study will use these two facets of equity, these are the equality or inequality in scholarship and loan distribution, and normative judgement of how equitably these distributions are both "horizontal equity" and vertical equity (Lau, 2001).

Proponents of student loans schemes argue that on equity grounds, "he who benefits should pay for that education" (Barden et al, 1991). It is common knowledge that higher education is very expensive and the recipients of higher education, on the average, enter higher income and higher status jobs than the less educated. So, why should the average or lower income taxpayers pay for the undoubted advantages education bestows on graduates? To do this offends both horizontal equity and vertical equity. It contradicts horizontal equity because the lower income taxpayers are subsidising the potential higher income groups, since after graduation, students earn higher incomes than those who have subsidised them before. It also offends vertical equity because the lower income taxpayers should be subsidised, instead of them subsidising the potential higher income groups.

Opponents of loan schemes may say that we should also consider equity between education and other activities. They argue that the loan expenditures fail to release government expenditure for other uses for many years because the government have to provide loan finance (Le Grand, 1989). This is because private banks are selective, and would not offer students with little collateral; loans which would be paid in the distant future. Hence, it is inequitable to taxpayers, who do not attend higher education, and also have to forego certain better facilities which would otherwise be provided by the government. However, this problem of opportunity cost can be overcome through securitisation (Dearing, 1997). If loans are privatised, the savings to the taxpayers are larger and hence funds would be released immediately for other government expenditures such as health services and transport.

In considering the equity argument about loans and grants, we should also examine the methods of repayment of loans with reference to the lifetime disposable income of the borrowers. According to Verry (1977), if the straight-repayment method is used, the loan has adverse distributional effects. As every graduate has the same amount to repay, these repayments will amount to a higher proportion of lifetime incomes for low earners than for high earners. In other words, such repayments represent a regressive tax. However, if income contingent loans are introduced, in which loans are 
repaid as a proportion of a graduate's incomes each year, the redistributive effect will be proportional to incomes. Hence, this type of loan is expected to be more favourable to low-income students. (Albrecht \& Ziderman, 1991). This would encourage the participation of lower income groups in higher education. However, the interest charged on income-contingent loans would also have life-long effects on repayments of loans. If the interest charged is close to the market rate, certain problems may arise. Low-income students, particularly may be discouraged from borrowing. Those who take up the loans would also require a longer time to repay them, which would increase the chance of default.

\footnotetext{
"The protection of Income-Contingent arrangements for the low paid means that a significant minority of graduates would be making repayments which did not even cover the interest on their loans, let alone repay the debt." (Dearing Report, July, 1997, p 328).
}

Consequently, the debts would continue to grow throughout one's life, and could never be written-off even with the income-contingency arrangement.

\section{Methodology}

The quantitative survey research method was employed for data collection. One set of questionnaires was administered to 736 undergraduates of two institutions of higher learning in Sibu, Sarawak in March 2018. 77 and 659 samples were collected from Institution A and B representing more than $35 \%$ and $45 \%$ respectively of their student population.

\section{The Questionnaire}

The questionnaire comprised the profile of the respondents including their gender, ethnicity, parental income, area coming from, type of financial support and opinion about income contingent loan as student financial support.

\section{Analysis}

Both descriptive and inferential statistics were employed to analyse the following research questions.

\section{Research Question 1:“How equitable are the scholarships and student loans in financing privately tertiary education at the SCORE region of Sarawak?}

Table 1 shows the provision and equity of scholarship distribution and its chisquare significance among four independent variables which are ethnicity, gender, areas and income groups of respondents.

Chi -square test shows no significant association between the provisions of scholarships and ethnicity with $\chi^{2}=1.244$; df $=2 ; p=0.537$ ). Column (2) of Table 1 shows that $8.2 \%$ and $6.0 \%$ of natives and non-natives respectively are provided with scholarships. The scholarship distribution therefore favours the natives in terms of type1 equality measurement, as indicated in Column (2).

Column (3) shows the racial composition of the Malaysian population in 2010 (latest population census), which was $67.4 \%$ native and $32.6 \%$ non-native. However, Column (4) shows that the provision of scholarships to natives $(29.2 \%)$ is much lower than its population share $(67.4 \%)$. In contrast, the provision of scholarships to non- 
natives $(70.8 \%)$ is much higher than its population share $(32.6 \%)$. Thus, non- natives are over-represented in their scholarship share whereas natives are under-represented, as indicated by the representation indices of 43.3 and 217.1 in column (5) for natives and non-natives respectively (a representative index of less than 100 shows underrepresentation, whereas over 100 means over-representation of the categories in the population share).

Table 1: Provision, and Equity of Scholarship Distribution for All Groups

\begin{tabular}{|c|c|c|c|c|}
\hline $\begin{array}{l}\text { Independent } \\
\text { Variables } \\
\text { (1) }\end{array}$ & $\begin{array}{l}\text { Provision of } \\
\text { Scholarships within } \\
\text { Groups (\%) } \\
\text { (Type-1 Equality) } \\
\text { (2) }\end{array}$ & $\begin{array}{l}\text { General } \\
\text { Population } \\
\text { Share (\%) } \\
\text { (3) } \\
\end{array}$ & $\begin{array}{l}\text { Proportions of } \\
\text { Scholarships } \\
\text { For Each } \\
\text { Group } \\
\text { (4) } \\
\end{array}$ & $\begin{array}{l}\text { Type-2 } \\
\text { Equality } \\
(\mathbf{5}) \\
=(4) \div(3) \\
\text { x100 }\end{array}$ \\
\hline \multicolumn{5}{|l|}{ Ethnicity } \\
\hline Native & $8.2 \%$ & $67.4 \%$ & $29.2 \%$ & 43.3 \\
\hline Non-native & $6.0 \%$ & $32.6 \%$ & $70.8 \%$ & 217.1 \\
\hline \multicolumn{5}{|l|}{ Gender } \\
\hline Female & $4.9 \%$ & $48.5 \%$ & $43.5 \%$ & 89.7 \\
\hline Male & $8.0 \%$ & $51.5 \%$ & $56.5 \%$ & 109.7 \\
\hline \multicolumn{5}{|l|}{ Areas } \\
\hline Rural & $6.3 \%$ & $29.0 \%$ & $22.9 \%$ & 78.9 \\
\hline Urban & $7.3 \%$ & $71 \%$ & $77.1 \%$ & 108.5 \\
\hline \multicolumn{5}{|l|}{ Income $\mathbf{G}^{*}$} \\
\hline Lowest & $8.5 \%$ & & & \\
\hline Low & $7.0 \%$ & & & \\
\hline Medium & $4.3 \%$ & & & \\
\hline High & $12.5 \%$ & & & \\
\hline Top-bracket & $8.6 \%$ & & & \\
\hline
\end{tabular}

The result also shows that there is no significant association between the provision of scholarships and gender, shown by the chi-square test, $\chi^{2}=5.59$; $\mathrm{df}=2 ; \mathrm{p}$ $=.076 .4 .9 \%$ and $8.0 \%$ of females and males receive scholarships respectively. In terms of type-1 equality, scholarships therefore slightly favour the males.

However, the provision of scholarships to female (43.5\%) is lower than its population share $(48.5 \%)$ as contrasted with the male counterparts. This means that males are over-represented in the provision of scholarships (109.7) than females (89.7), as shown by representative indices in column (5) in comparison of the general population share. Thus, scholarship provision is also inequitable to females in terms of type- 2 equality measurement.

There is no significant association between the provision of scholarships and the areas, which respondents come from $\left(\chi^{2}=0.487 ; \mathrm{df}=2 ; \mathrm{p}=.784\right)$. The provision of scholarships favours the respondents from urban areas in terms of type- 1 equality measurement, as $6.3 \%$ and $7.3 \%$ of rural and urban undergraduates are respectively being provided with scholarships. Thus, the government's effort to minimise poverty 
especially in the rural areas, has not been encouraged by the present distribution of scholarships on vertical equity grounds.

In terms of type- 2 equality, the provision of scholarships to the rural areas $(22.9 \%)$ is lower than their population share $(29.0 \%)$ as compared to respondents in the urban areas $(77.1 \%)$ which is higher than their population share $(71.0 \%)$. Thus, the scholarship distribution favours those from the urban areas, as can be also shown by the representation indices of 78.9 and 108.5 for rural and urban areas respectively. Thus, this violates he vertical equity of helping the rural poor in eradicating poverty.

The provision of scholarships in percentages across income groups is significant $\left(\chi^{2}=14.568 ; \mathrm{df}=4 ; \mathrm{p}=.005\right)$ as indicated in Table 1 for examining its type- 1 equality measurement. Type-1 equality measurement shows that the distribution of scholarships indicated a mixed result. The scholarship distribution favours the high income group most, followed by the top-bracket, lowest, low and medium income-groups. The result indicates that the scholarship distribution seems to be inequitable to the low and lowest income groups. In terms of vertical equity, this notion of equity is offended since lower income groups receive proportionately fewer scholarship than higher income groups.

Subsequently, the equity analysis of loans on ethnicity, gender, areas respondents coming from and income groups is shown in Table 2. There is a significant association between the provision of loans and ethnic groups with $\chi^{2}=16.36 ; \mathrm{df}=2 ; \mathrm{p}=.000$. Also, Column (2) of Table 2 indicates that $65.9 \%$ and $80.7 \%$ of natives and non-natives respectively received loans. Therefore, the loan distribution favours non-natives rather than natives in terms of type-1 equality measurement.

In terms of type-2 equality, the provision of loans (19.7\%) to natives, is much lower than their share in the population $(67.4 \%)$. In contrast, the provision of loans to non- natives $(80.3 \%)$ is higher than their share in the population $(32.6 \%)$. In other words, non-natives are over-represented whereas natives are under-represented in loan distribution, as indicated by the representation index in column (5) which are 29.2 and 247.8 for natives and non-natives respectively.

There is also a significant association between the provision of loans and gender $\left(\chi^{2}=6.98 ; \mathrm{df}=2 ; \mathrm{p}=.037\right)$. Column (2) of Table 2 shows that $80.3 \%$ and $74.3 \%$ of females and males respectively receive loans. Thus, loan provision favours females over males. For type- 2 equality, females are over-represented in the loan provision whereas males are under-represented, indicated by the representation indices of 118.2 and 82.9 respectively in column (5).

Table 2: Provision, and Equity of Loan Distribution for All Groups

\begin{tabular}{|c|c|c|c|c|}
\hline $\begin{array}{l}\text { Independent } \\
\text { Variables } \\
\text { (1) }\end{array}$ & $\begin{array}{l}\text { Provision of Loans } \\
\text { within Groups (\%) } \\
\text { (Type-1 Equality) } \\
\text { (2) }\end{array}$ & $\begin{array}{l}\text { General } \\
\text { Population } \\
\text { Share (\%) } \\
(3) \\
\end{array}$ & $\begin{array}{l}\text { Proportions } \\
\text { of Loans } \\
\text { For Each } \\
\text { Group } \\
\text { (4) } \\
\end{array}$ & $\begin{array}{l}\text { Type-2 } \\
\text { Equality } \\
(5) \\
=(4) \div(3) \\
x 100\end{array}$ \\
\hline $\begin{array}{l}\text { Ethnicity* } \\
\text { Native }\end{array}$ & $65.9 \%$ & $67.4 \%$ & $19.7 \%$ & 29.2 \\
\hline $\begin{array}{l}\text { Non-native } \\
\text { Gender* }\end{array}$ & $80.7 \%$ & $32.4 \%$ & $80.3 \%$ & 247.8 \\
\hline Female & $80.3 \%$ & $48.5 \%$ & $57.3 \%$ & 118.2 \\
\hline Male & $74.3 \%$ & $51.5 \%$ & $42.7 \%$ & 82.9 \\
\hline
\end{tabular}




$\begin{array}{lllll}\text { Areas } & & & & \\ \text { Rural } & 74.2 \% & 29.0 \% & 22.9 \% & 78.9 \\ \text { Urban } & 78.3 \% & 71.0 \% & 77.1 \% & 108.5 \\ \text { Income G* } & & & & \\ \text { Lowest } & 77.1 \% & & & \\ \text { Low } & 80.4 \% & & & \\ \text { Medium } & 77.8 \% & & & \\ \text { High } & 50.0 \% & & & \\ \text { Top-bracket } & 54.3 \% & & \\ \text { *P }<\mathbf{0 . 0 1} \text {; Sample Size }=\mathbf{7 3 6}\end{array}$

For areas, the rural-urban dichotomy is used. There is no significant association between the provision of loans and areas of respondents' origin with $\chi^{2}=1.321$; $\mathrm{df}=2$; $\mathrm{p}=.516$. Column (2) of Table 2 shows that $78.3 \%$ and $74.2 \%$ of the urban and rural undergraduates are respectively provided with loans. Thus loan provision favours urban respondents in terms of type-1 equality.

In terms of type-2 Equality measurement, the share of loans to the urban respondents $(77.1 \%)$, is more than their share of the total population $(71.0 \%)$. In contrast, the percentage of loans given to rural respondents $(22.9 \%)$ is less than their share in the population $(29.0 \%)$. Thus, the loan distribution favours those from the urban areas. This inequality can also be shown by the representation indices of 108.6 and 78.9 for the urban and rural areas respectively, as indicated in column (5).

In terms of income, there is a significant association between the provision of loans and income-groups with $\chi^{2}=21.27$; $\mathrm{df}=10 ; \mathrm{p}=.019$. Column (2) shows that 80.4, $77.8 \%, 77.1 \%, 54.3 \%$ and $50 \%$ of the low, medium, lowest, top-bracket and high income groups were provided with loans. This suggests that the loan provision shows a mixed result. The lowest income-group was not being treated preferentially in terms of vertical equity argument, following objectives of the New Economic Policy (NEP) and National Development Policy (NDP).

\section{Multiple Logistic Regressions}

The multiple logistic regression model is used when all independent variables are entered together in the model to take into account of interrelationships. The "Enter" method is used. The model can be written as:

$$
\text { Logit } P_{i}=a+b_{1} X_{i}+b_{2} X_{2 i} \quad+b_{3} X_{3 i}+\ldots \ldots . . b_{n} X
$$

ni $\ldots . . . . . . . . . . . . . . . . .(1)$

where a denotes the constant, $\mathrm{b}_{1}, \mathrm{~b}_{2} \ldots \ldots \mathrm{b}_{\mathrm{n}}$ denotes how much higher the log odds are for non-reference categories than reference categories to have a scholarship. $X_{1}, X_{2} \ldots X_{n}$ denotes independent variables. The model is shown in table 3 below.

Table 3: Interrelationships of Independent Variables, Scholarship Provision

$\begin{array}{lcccc}\text { Independent } & \text { Reference } & \text { B } & \text { Significance } & \text { Exponential } \\ \text { Variables (1) } & \text { Categories (2) } & (3) & \text { (4) } & \text { (5) }\end{array}$




\begin{tabular}{lllll}
\hline Race & Native $=0$ & -0.329 & 0.348 & 0.720 \\
Gender & Female $=0$ & 0.554 & 0.075 & 1.740 \\
Areas & Rural $=0$ & -0.108 & 0.770 & 0.898
\end{tabular}

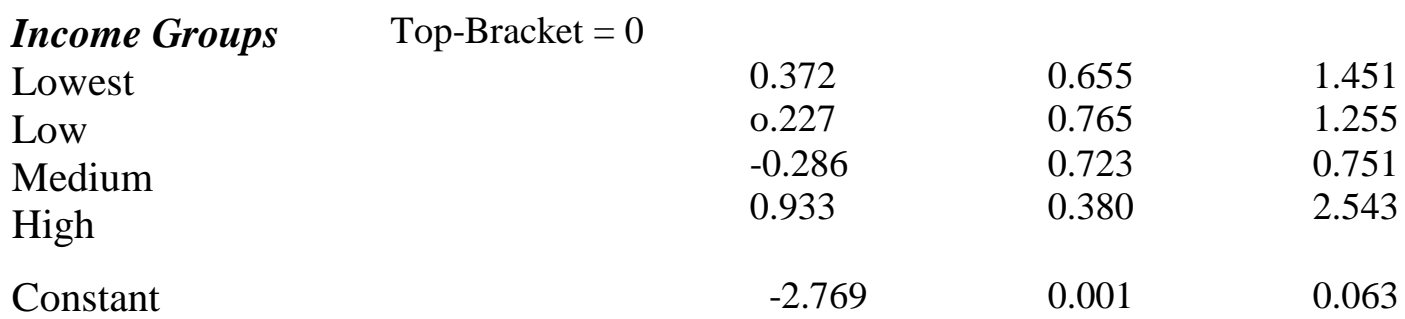

Table 3 shows that all independent variables are not statistically significant in terms of the Wald statistic in the provision of scholarships, as indicated in Column (4). Taking into account the interrelationships of all the variables which are included in the model, the model shows the relative odds for members of a non-reference category to have scholarships, as compared to those of a reference category. Thus, scholarship provision favours natives over non-natives as the odds of a non-native having a scholarship are only 0.720 times $(72 \%)$ those of a native (reference category) as indicated in Column (5).

Subsequently, a male (reference category) has a better chance of having a scholarship than a female (the odds of a male having a scholarship are 1.740 times (174\%) those of a female). In addition, respondents from rural areas (reference category) have higher odds of receiving a scholarship than those from urban area, as the odds of respondents from the urban area having scholarships is only about $0.898(89.8 \%)$ of those from the urban. Scholarship provision most favours respondents from the high income group. The lowest, low, top-bracket (reference category) and medium income groups follow this. Thus, the odds for high, lowest, low and medium income groups are respectively $2.543,1.451,1.255$ and 0.751 times of those in the top bracket.

Table 4: Interrelationships of Independent Variables, Loan Provision

\begin{tabular}{llccc}
\multicolumn{1}{c}{$\begin{array}{c}\text { Independent } \\
\text { Variables (1) }\end{array}$} & $\begin{array}{c}\text { Reference } \\
\text { Categories (2) }\end{array}$ & $\begin{array}{c}\text { B } \\
\text { (3) }\end{array}$ & $\begin{array}{c}\text { Significance } \\
\mathbf{( 4 )}\end{array}$ & $\begin{array}{c}\text { Exponential } \\
\text { (5) }\end{array}$ \\
\hline Race & Native $=0$ & 0.714 & 0.000 & 2.043 \\
Gender & Female $=0$ & -0.421 & 0.024 & 0.656 \\
Areas & Rural = 0 & 0.138 & 0.536 & 1.148 \\
Urban & & & & \\
Income Groups & Top-Bracket $=0$ & & & \\
Lowest & & 1.011 & 0.022 & 2.747 \\
Low & & 1.153 & 0.002 & 3.169 \\
Medium & & 1.012 & 0.010 & 2.752 \\
High & & -0.347 & 0.588 & 0.707 \\
Constant & & -0.157 & 0.702 & 0.854
\end{tabular}


The same model employed as in the case of scholarship provision can be used for loan provision.

Table 4 above shows that such independent variables as race, gender, lowest. Low and medium income groups which respondents come from are statistically significant in the provision of loans, as indicated in column (4). However, area is statistically not significant in the provision of loans.

Column (5) indicates that the provision of loans favours non- natives over natives, as the odds of a non-native receiving a loan are 2.043 times $(204 \%)$ that of a native. The loan distribution also favours females over males, as the odds of a male respondent receiving a loan are only 0.656 times $(65.6 \%)$ that of a female respondent. Similarly, urban respondents are more likely to be offered with loans, as their odds of having loans are 1.148 times $(115 \%)$ those of rural respondents. As far as income groups are concerned, the loan provision most favours respondents from the low income group. The medium, lowest, top-bracket and high groups follow this. In other words, the odds of respondents from the lowest, low, medium, and high-income groups are respectively $2.747,3.169,2.752$, and 0.707 times than those of the top-bracket to be provided with a loan.

\section{Research Question 2: "How do student loans and scholarships differ in terms of probability by employing multiple logistic regression analysis?"}

To find the probability of a respondent with certain characteristics given in the sample having a scholarship, we can transform the log odds into probability form as:

$\mathrm{P}($ event $)=1 \div\left(1+\mathrm{e}^{-\mathrm{z}}\right)$

Whereby $\mathrm{P}$ is the probability of having a scholarship, and e is the base of natural logarithms, approximately 2.718 (Norusis, 1990, p120).

Where $\mathrm{Z}$ is the linear combination of independent variables, the equation can be written as

$\mathrm{Z}=\mathrm{Bo}+\mathrm{B}_{1} \mathrm{X}_{1}+\mathrm{B}_{2} \mathrm{X}_{2}+$ $\mathrm{B}_{\mathrm{p}} \mathrm{X}_{\mathrm{p}}$

$\mathrm{B}_{\mathrm{o}}$ and $\mathrm{B}_{1}$ are coefficients or log odds estimated from the data. $\mathrm{X}_{1} \ldots . . \mathrm{X}_{\mathrm{p}}$ are the independent variables. Thus, the model 8.4 can be used for predicting the probability of having a scholarship. For example, a non-native belonging to low-income group is estimated as having a $1.2 \%$ chance of having a scholarship. This can be calculated as:

$Z=(-0.329 \times 1)+(0.227 \times 1)+(-2.769 \times 1)=-2.871$

The value -2.871 can be expressed as $\mathrm{e}^{-2.871}$, the base of natural logarithms. The logit is $\mathrm{e}^{-(-2.871)}$ which is used in calculating the probability of having scholarships by using equation (3) above. The probability of having a scholarship is therefore estimated as $=(1) \div\left\{1+\mathrm{e}^{-(-2.871)}\right\}=(1) \div\left(1+\mathrm{e}^{2.871}\right)=0.053=5.3 \%$.

Table 5 compares that the probability of having scholarships and loans 
Table 5: Comparing the Probability of Having a Scholarship and a Loan for Students with Various Characteristics

\begin{tabular}{lll}
\hline Characteristics & Scholarships & Loans \\
\hline Non-native, urban & $0.041=4.1 \%$ & $0.070=70.0 \%$ \\
Non-native, low-income & $0.053=5.3 \%$ & $0.847=84.7 \%$ \\
Native, rural, female & $0.059=5.9 \%$ & $0.461=46.1 \%$ \\
Native, rural, male & $0.098=9.8 \%$ & $0.359=35.9 \%$ \\
Non-native, urban, male, medium income & $0.051=5.1 \%$ & $0.499=49.9 \%$ \\
Native, urban, female & $0.053=5.3 \%$ & $0.495=49.5 \%$ \\
Non-native, rural, female, low income & $0.053=5.3 \%$ & $0.847=84.7 \%$ \\
Non-native, male, urban & $0.058=5.8 \%$ & $0.568=56.8 \%$ \\
Non-native, male, rural & $0.073=7.3 \%$ & $0.534=53.4 \%$ \\
Native, rural, male, lowest income & $0.084=8.4 \%$ & $0.606=60.6 \%$ \\
Native, urban, male & $0.089=8.9 \%$ & $0.392=39.2 \%$ \\
Native, rural, male & $0.098=9.8 \%$ & $0.359=35.9 \%$ \\
Non-native, Urban, male, high income & $0.125=12.5 \%$ & $0.482=48.2 \%$ \\
Native, male, rural, high income & $0.218=21.8 \%$ & $0.461=46.1 \%$ \\
\hline
\end{tabular}

Table 5 shows that scholarships and loans contrast distinctly with one another. Given the same characteristics, the probability of having scholarships is low when the probability of having loans is high, and vice-versa. This is mainly because of different criteria used in the awards of loans and scholarships.

\section{Research Question 3: "What are the opinion of undergraduates on loans as a mechanism of financing the teacher education?”}

\section{Table 6 : Opinion of the Graduates on loans as Mechanism of Financing Teacher \\ Education}

Opinion Statements/ Responses

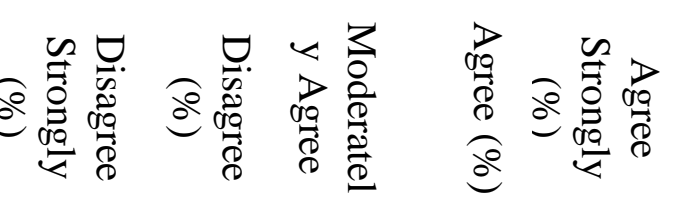

i. There is no problem in loan repayment if it is linked

\section{6}

11.8

1.8

43.6

to my income

ii. Unemployed married women should not have to

12.2

37.6

$15.1 \quad 9.0$

repay the loans

iii. Women may refuse mortgage loans for financing

9.0

17.

higher education because of fear of carrying debts

when getting married later on

iv. The repayment of loan amount depends on the 1.8

$\begin{array}{llll}6.3 & 34.4 & 32.6 & 21.6\end{array}$ income level

v. Education loans should be interest free

$\begin{array}{lllll}6.5 & 6.7 & 23.1 & 20.1 & 39.8\end{array}$



parental income

vii. The government should give scholarships/grants instead of loans to very poor students

viii. Bigger amounts of loans should be given to more expensive courses than cheaper courses

ix. A loan recipient will study harder, as he/she pays forhis/her own education

$\mathrm{x}$. The financial support given should depend on the academic results of students

Scale reliability $=0.701 ; \mathrm{n}=736$

Statements (i) - (ix) in Table 6 seek the opinions of fresh graduates regarding loans as a form of financial support which may have different effects on different groups of people. Statement (x) seeks the opinion of fresh graduates on the incentive would be given to those who score excellently as rewards. The questionnaire survey as illustrated in Table 6 shows high percentages of positive responses on all the items as listed.

\section{Conclusion}

The main purpose of the study is to investigate how equitable is the provision of scholarships and loans in the SCORE region of Sarawak while attempting to answer the open question, "loans or grants". The independent variables are ethnicity, gender, areas which respondents come from and their parental income.

For scholarships, both cross-tabulations and multiple logistic regressions also indicate that the scholarship distributions favour male over female and urban over rural respectively in terms of type- 1 and type- 2 equality measurements. However, crosstabulation analysis shows that the scholarship distribution favours native in terms of type- 1 equality but non-natives for type- 2 equality. The multiple regression analysis also indicates that native had more scholarship support than no-natives. Thus, this supports the government policy of positive discrimination towards the natives embedded in the NEP and NDP.

The fact that urban undergraduates were given more scholarships than the rural counterparts does not accord with the government's policy of eradicating hard-core poverty and of minimising the poverty in the rural areas through supporting higher education.

Furthermore, the incidence of poverty in the rural areas is 5.3 times higher than that in the urban areas. (The Centre for Poverty and Development Studies, 2016). Thus, an even greater share of scholarships should be given to those from the rural areas on vertical equity grounds as rural undergraduates receive only 0.898 times of scholarships than those from the urban areas. This is especially the case when the poor have to consider the opportunity costs foregone (Lau, 2001).

For the income groups, both cross-tabulations and multiple regression analyses yield similar results whereby the high income group receives most scholarship, followed by the top-bracket, lowest, low and medium income groups. Thus, scholarship distribution is inequitable to lower income groups in terms of both horizontal and 
vertical equity arguments and do not follow the government objective of minimising poverty.

On the other hand, both cross-tabulations and multiple logistic regressions indicate that the loan distribution favour non-natives over natives, female over male and urban over rural respectively and also in terms of type- 1 and type- 2 equality measurements. This implies that natives were not treated preferentially as they had less loan support barring them to gain access to private university education in the SCORE region of Sarawak because of financial constraints.

Moreover, the positive discrimination towards females in the offer of loans may align with the government policy of encouraging female participation in the economy $\{\mathrm{Lau}, 2001\}$. Subsequently, the loan provision which favours undergraduates from the urban areas implies that "unequal treatment of unequals" is not promoted for undergraduates coming from rural areas and therefore not aligned with the New Economic Policy and National Development Policy of tending to eradicate or minimise poverty in rural areas.

However, for the income groupings, it shows mixed results respectively when using both cross-tabulations and multiple logistic regressions analysis. The loan provision favours most the low income group followed by medium, lowest, top-bracket and high income groups.

To summarise, the financial support to the undergraduates studying at the two private Institutions of higher learning in the SCORE regions is not equitable in terms of horizontal and vertical equity arguments according to ethnicity, gender, areas which respondents come from and income groups. Perhaps these inequities have been offset by the financial support given to the undergraduates who pursue their studies in the public universities (Lau, 2001).

Remarks from Editor-in-Chief: The Editorial Board of Borneo Journal of Social Sciences and Humanities would like to express earnest appreciation to all those who have contributed their articles to this inaugural issue of the Journal. You have helped to start an important milestone in the research and publication of UCTS. My sincere appreciation also goes to UCTS for sponsoring the Internal grant to make this research possible.

\section{References}

Albrecht, D. \& Ziderman, A. (1991). Deferred Cost Recovery For Higher Education: Student Loans Programs in Developing Countries. The World Bank Discussion Papers, No 137, Washington, D.C.

Barden, L. et al (1991). An Analysis of Student Loan option. London: The Committee of Vice-Chancellors and Principals of the Universities of the United Kingdom (CVCP).

Brewer, D. J. \& McEwan,P.J.(2010). Theoretical Concepts in the Economics of Education In Brewer D. J. et al (ed) Economics of Education, Elsevier: San Diego, 3-12. Barr, N. (1989). Student Loans: The Next Steps._ Aberdeen: Aberdeen University Press.

Clive R. Belfield (2015) Economic Principles for Education, Theory and Practice. Edward Elgar: London

Cohn, E. \& Geske, T. (1990). The Economics of Education. Fourth Edition, Oxford: Pergamon Press. 
Eide,S. (2010). Human Capital In Brewer D. J. et al. (ed) Economics of Education, Elsevier: San Diego, 27-43.

Lau, H.S. (2015). Economics of Financing Teacher Education: The Case of Teacher Education Institutes in Malaysia. South East Asia Journal of Contemporary Business, Economics and Law. Vol.6, Issue 3 (Apr.) 1-10.

Lau, H.S. (2001)._Financing of Higher Education in Malaysia: An Equity and Efficiency Analysis of Student Loans and Scholarships, Ph.D Thesis, March, 2001, Institute of Education, University of London.

Le Grand, J.L. \& Robinson, R., (1989). The Economics of Social Problems: The Market versus the State, London: Macmillan.

Murphy, R., Scott-Clayton J., \& Wyness, G. (2018). The End of Free College in England: Implications for Quality, Enrolments and Equity. CEP Discussion Paper No. 1501(Revised Version 2018). LSE.

Gaddah, M. \& Munro, A (2011). The Rich or the Poor: Who Gains from Public Education Spending in Ghana? GRIPS Discussion Paper 11-12, National Institutes for Policy Studies, Japan.

McMahon, W. W. (1982). Efficiency and Equity criteria for Educational Budgeting and Finance in McMahon, W.W. and Geske, T. G. (eds) Financing Education: Overcoming Inefficiency and Inequity, Urbana: University Of Illinois Press.

Mace, J. (1987). Economics and Finance of Education Block 1, Unit 10. Institute of Education, University of London.

Monk, D. H. (1990). Educational Finance: An Economic Approach. New York: McGraw Hill Publishing Co.

Norusis, M.J. (1990). SPSS/PC ${ }^{+}$Advanced Statistics 4.0 For the IBM PC/XT/AT and $P S / 2$, Chicago: SPSS Inc.

Verry, D. (1977). Some Distributional and Equity Aspects of the Student Loans Debate in Economics and Educational Policy, Block V, Open University.

Weiss, E.B. (1992). Intergenerational Equity, a Legal Framework for Global Environmental Change in Weiss, E. B edited Environmental Change and International Law: New Challenges and Dimensions, Tokyo: United Nations University Press, 1992.

Wilson, P.L. (1996). State/Social Mechanisms for University Students' Financial Support: Modes of Students' Participation in Financing the Cost of Higher Education, Higher Education Management, Vol. 8, No.1, 113-121.

Woodhall, M. (1989) International Experience of Financial Support for Students: Recent Trends and Developments in Woodhall, M., (ed) Financial Support For Students: Grants, Loans Or Graduate Tax?_London: Kogan Page.

Woodhall, M. (2007). Funding Higher Education: The Contribution of Economic Thinking to Debate and Policy Development in Education Working Paper series, Number 8, December 2007, The World Bank Publication: Washington, D.C. 